\title{
Sports for the disabled: the evolution from rehabilitation to competitive sport
}

A historic review of sports for the disabled can be undertaken from a number of different approaches. First of all, the concepts which led to its origin and early development have evolved and changed considerably over time. The range of sports and the numbers of participants have increased. The early perceptions of limits to performance by reason of impairment proved to be inaccurate and as they have become less restricted performance has continued to expand. The role of sports medicine in studying and measuring performance and in demonstrating the training possibilities of athletes with disabilities has continued to grow. Finally, sports participation by the disabled has served as a vivid illustration of success and achievement to the public at large, who are very aware of what athletic accomplishment means in physical and psychological terms. Athletes themselves see sports as a pathway to integration in society, and there are those who look forward to Olympic integration not just with demonstration events but with full participation in medal events at the regular Olympic Games.

Sports participation has contributed significantly to the field of clinical rehabilitation. It was introduced as part of a patients's hospital programme by Guttman n 1944. He recognised the physiological and psychological values of sport in the management of paraplegic hospital inpatients, and in his early writings this was his persistent message. ${ }^{1}$ For some years development continued within the medical rehabilitation environment, and studies through the early seventies reflected this influence. ${ }^{23}$ Sports physiologists and biomechanists also showed some interest in analysing performance in particular sports. ${ }^{4}$ From those beginnings, sports for the disabled has developed beyond rehabilitation sport to include within its spectrum sports for recreation, health, fitness, and competition. The ultimate competitive model, paralympic level participation, was achieved in 1960, when the first Paralympic Games were held in Rome, following the Olympic Games of that year. The 400 participants were all spinal injured. The paralympic sports movement now includes not only spinal injured, but also amputees, blind people, and athletes with cerebral palsy. This year in the Atlanta Paralympics, there were 3500 competitors representing 120 countries. The staging of two demonstration wheelchair track races, a men's 1500 and a women's 800 metre event in the Atlanta Olympics is a further illustration of how far the concept of competitive sports for the disabled has advanced since the first paralympics in 1960.

The advances in sports performance which have occurred in a 50 year lifespan are impressive. However, performance interpretation must be related to the level of underlying physical impairment to be meaningful. This difficulty has been managed to an extent through the athlete classification system, designed to create fair competition by grouping together athletes with a similar range of performance potential. ${ }^{5} \mathrm{~A}$ review of paralympic performance in $1500 \mathrm{~m}$ track from 1976 through 1992 is illustrative. In the 1976 Toronto Olympiad the $1500 \mathrm{~m}$ distance was run for the first time. Paraplegics with low neurological injury level alone (high performance capacity) were considered capable of this performance level. From the initial record of 5:18.60, steady improvement of performance over the years resulted in a time of 3:17.56 in 1992. Remarkably, the tetraplegic C6 class $1500 \mathrm{~m}$ race in 1992 was run in the time of $5: 13.69$, better than the paraplegic class time in 1976.

The entry of wheelchair competitors into able bodied road racing represented a major milestone in the development of wheelchair sports, both in terms of new sports medicine challenges and in terms of athletic performance. ${ }^{6}$ Since the first appearance of a wheelchair athlete in the 1977 Boston Marathon the wheelchair division of the Boston Marathon has achieved recognition as a premier event, being the forerunner of many wheelchair marathons throughout the world. Bobby Hall of Massachusetts, the wheeler who singlehandedly achieved this breakthrough, achieved a time of 2 hours 45 minutes in the first recorded wheelchair marathon. Again to illustrate advances in performance, the Boston wheelchair marathon has recently been run repeatedly in under 1 hour 30 minutes.

Early wheelchair exercise studies occurred in the setting of medical rehabilitation. ${ }^{78}$ The first reported study of paralympic competitors was in the 1972 Heidelberg paralympics. ${ }^{9}$ However, it was not until the 1976 Toronto Olympiad that the exercise capacity of athletes with spinal injury was allowed full expression through longer distance track events. Since then, studies continue to provide further understanding of the improving performance of wheelchair athletes, and their capacity for training. ${ }^{10-12}$

From its earlier beginnings as a rehabilitation tool, sport for the disabled has evolved into an increasingly integrated and competition oriented activity involving specialised coaching and training. Its growing sophistication has led to new challenges as it grapples with its own internal politics. There is some concern regarding what is perceived as an overemphasis on integrating with able bodied sports at the Olympic level. It is recognised that this ideal is both more achievable and more attractive to the competitors with lesser impairments. They demonstrate the highest absolute level of performance, closest in many respects to the able bodied model. The more severely impaired, despite great excellence of performance in physiological terms, present as a less exciting performance in absolute terms and are at great risk of elimination from elite level competition.

This concern is compounded by the attempt to group together all disability types represented by individuals with spinal cord pathology, musculoskeletal impairments, and movement disorders such as cerebral palsy. The various international federations of sport for the disabled are currently grappling with this conceptual issue.

CAIRBRE McCANN

Maine Medical Center, Portland, Maine, USA

1 Guttman L. Sport. In: Spinal cord injuries. Comprehensive management and research, 2nd ed. Oxford: Blackwell Scientific Publications, 1976:616-28.

2 Guttman L. Experimental studies on the value of archery in paraplegia. Paraplegia 1973;11:159-65.

3 Engel P, Hildebrandt G. Long-term spiroergometric studies of paraplegics during the clinical period of rehabilitation. Paraplegia 1973;11:105-10.

during the clinical period of rehabilitation. Paraplegia 1973;11:105-10.
Persyn U, Surmont E, Wouters L, De Maeyer J. Analysis of techniques used by swimmers in the para-Olympic games. In: Clarys JP, Lewillie L ed. Swimming 11. Baltimore: University Park Press: 1975:276-81.

McCann BC. Classification of the locomotor disabled for competitive sports: theory and practice. Int $\mathcal{f}$ Sports Med 1984;5(suppl):167-70.

6 Corcoran PJ, Goldman RF, Hoerner EF, Kling C, Knuttgen HG, Marqui Corcoran PJ, Goldman RF, Hoerner EF, Kling C, Knuttgen HG, Marquis
B, et al. Sports medicine and the physiology of wheelchair marathon racing. Orthop Clin North Am 1980;11:697-716. 
7 Voigt ED, Bahn D. Metabolism and pulse rate in physically handicapped when propelling a wheelchair up an incline. Scand f Rehab Med 1969;1: $101-6$.

8 Hjeltnes N. Oxygen uptake and cardiac output in graded arm exercises in paraplegics with low level spinal lesions. Scand $\mathcal{F}$ Rehab Med 1977;9:10713.

9 Hulleman K-D, List M, Matthes D, Wiese G, Zika D. Spiroergometric and telemetric investigations during the XX1 International Stoke Mandeville Games 1972 in Heidelberg. Paraplegia 1975;13:109-23.
10 Davis GM, Shephard RJ. Strength training for wheelchair users. $\mathrm{Br} \mathcal{F}$ Sports Med 1990;24:25-30.

11 Davis GM, Plyley MJ, Shephard RJ. Gains of cardiorespiratory fitness with arm-cranking training in spinally disabled men. Can $\mathcal{f}$ Sport Sci 1991;16:64-72.

12 Veeger HEJ, Yahmed MH, van der Woude LHV, Charpentier P. Peak oxygen uptake and maximal aerobic power output of Olympic wheelchairdependent athletes. Med Sci Sports Exerc 1991;23:1201-9.

\section{A national strategy for the promotion of physical activity}

Three years ago, as part of the Health of the Nation strategy, the Government appointed a Physical Activity Task Force. It was charged with developing detailed national strategies for the promotion of physical activity. It was asked to consider gaps in current knowledge and to suggest means of filling them. Its remit also included the development of proposals and recommendations for taking the work forward and for monitoring progress in achieving specific targets.

The task force began its work in the confidence that the international scientific literature supported the case for exercise, and was sufficient for evidence based action. It perceived that the health benefits to be gained from a physically active lifestyle are real, well documented, and widely accepted as an important public health measure. Its notice was drawn to very many studies confirming that physical inactivity is very deleterious to health and a major risk factor for many chronic diseases, including coronary heart disease, stroke, obesity, high blood pressure, and osteoporosis. This evidence is drawn from epidemiological, clinical, and physiological studies.

The proposals from the task force were contained in a consultation paper "More People More Active More Often". This document, and the replies which it elicited from a wide variety of interested organisations, led to the government's strategy statement for physical activity, ${ }^{2}$ published earlier this year (19 March). The statement contains a summary of the recommendations from the task force and sets three key objectives (see below).

The consultation paper informed the Health Education Authority's new campaign, ACTIVE for LIFE, launched on the same day as publication of the strategy. The campaign represents the start of a well funded promotion designed to encourage physical activity as part of a healthy lifestyle. This will be a more sustained campaign than has previously been attempted.

It is only recently that the scientific case for the importance of regular participation in physical exercise has been accepted as sound and compelling by key professional bodies. A Working Party of the Royal College of Physicians of England, convened in $1989,{ }^{3}$ examined this evidence, recognised its importance and based a series of recommendations upon it. The American Heart Association recognized physical inactivity as a major risk factor for development of coronary heart disease only in $1993 .^{4}$ The general population appears to have accepted the message more rapidly: in $199075 \%$ of adults responding to the Allied Dunbar National Fitness Survey accepted that regular exercise conferred health benefits, though there had not been a corresponding change in exercise behaviour.

\section{New recommendations}

About the same time as the first meeting of the task force a new recommendation regarding physical activity was released in the United States by the American College of
Sports Medicine, the Centers for Disease Control, and the President's Council for Physical Fitness and Sport Recommendation (1993)..$^{5}$ The recommendation has been reinforced by the recent publication of the US Surgeon General's report. ${ }^{6}$ This recommendation proposes that "every American adult should accumulate 30 minutes or more of moderate intensity physical activity over the course of most days of the week. Because most Americans do not presently meet the standard described above, almost all should strive to increase their participation in moderate and/or vigorous physical activity". The task force was satisfied that the evidence in favour of moderate intensity exercise was sufficient to serve as a basis for target setting and was likely to be effective for the majority of people. It accepted the US recommendation and it has been incorporated into the government strategy. It places the emphasis on epidemiological evidence, on the weekly volume of physical activity, and on the importance of overall energy expenditure. An element of doubt remains regarding the answers to three questions.

(1) Will it be confirmed that moderate intensity exercise is adequate for all important health benefits? This is a reasonable interpretation of existing evidence. However, we can expect this to be challenged from time to time by new findings suggesting that it is "vigorous" intensity exercise which is important after all.

(2) Does the same benefit accrue if time spent exercising is an accumulation of short bouts? It has been suggested that the accumulation of several shorter bouts of exercise (say three bouts of 10 minutes) may be as beneficial as 30 minutes of sustained activity. ${ }^{7}$ Certainly the approach is attractive to those who wish to promote physical activity.

(3) Can habitual levels of physical activity be measured and documental reliably over time? This will continue to present significant practical difficulties. Without such evidence the monitoring of long term interventions will prove problematic and important critical answers will remain elusive.

The Allied Dunbar National Fitness Survey (ADNFS) ${ }^{8}$ measured physical activity, fitness, and attitudes towards and beliefs about physical activity. The findings suggested that something has to be done. About one third of the adult population between 16 and 74 years of age was sedentary, reporting no physical activity of moderate intensity or above, that is, less than one occasion, on average, lasting at least 30 minutes per week in the previous four weeks (in other words, less than three occasions in a month). A quarter of young women aged between 16 and 24 were sedentary. Less than a third of all adults achieved an acceptable level of moderate intensity physical activity as recommended in the published strategy. The task force received reassurances that population shifts in exercise behaviour had been brought about in 